\title{
Surgical Treatment of Postoperative Abdominal Metastases of Hepatocellular Carcinoma: 10-Year Experience in a Single Center
}

\author{
Jiong-Ze Fang* \\ Yong Yang (D* \\ Hong-Da Zhu \\ Jian-Nan Sun \\ Hong-Chao Mi \\ Cai-De Lu
}

Department of Hepatopancreatobiliary Surgery, Ningbo Medical Centre Lihuili Hospital, Ningbo University, Ningbo,

Zhejiang, People's Republic of China

*These authors contributed equally to this work
Correspondence: Cai-De Lu

Tel/Fax +86 574- 55835600

Email lucaide@nbu.edu.cn
Objective: The significance of surgical treatment was analyzed by retrospectively collecting data on the re-resection of intra-abdominal metastases after hepatocellular carcinoma (HCC) surgery in our center over the past 10 years.

Methods: The clinical and pathological data of 15 patients who developed intra-abdominal metastases after HCC resection and underwent re-resection from January 2010 to January 2020 were collected to analyze the patients' characteristics and prognosis.

Results: Of the 15 cases of abdominal metastasis, the majority ( 8 cases) had greater omental metastasis. There were 4 cases of mesenteric metastases, 1 case of abdominal wall metastasis, 1 case of mesenteric plus rectal wall metastasis, and 1 case of colon and mesenteric metastasis. The 1-year, 3-year, and 5-year disease-free survival (DFS) rates were 31.1\%, $23.3 \%$, and $11.7 \%$, respectively. The 1-year, 3-year, and 5-year overall survival rates were $93.3 \%, 28.7 \%$, and $19.1 \%$, respectively. Three patients are currently surviving disease-free, with survival times of 130.4 months, 43.3 months, and 9.4 months, respectively.

Conclusion: Although the current guidelines do not recommend surgical resection as the preferred treatment for postoperative abdominal metastases of HCC, surgical resection is recommended for patients with limited or solitary metastasis in the abdominal cavity.

Keywords: hepatocellular carcinoma, postoperative recurrence of HCC, intra-abdominal metastasis, disease-free survival, overall survival

\section{Introduction}

Hepatocellular carcinoma (HCC) is a common malignant tumor in China. According to the latest report of the International Agency for Research on Cancer of the World Health Organization, there were 410,000 new cases of HCC in China and 390,000 deaths in 2020, which is a serious threat to public health. ${ }^{1}$ Although targeted and immunotherapy for HCC have made great progress in recent years, surgical resection is still the most effective way to treat $\mathrm{HCC}$, and postoperative recurrence is the main factor affecting the overall survival (OS) time of patients. Most postoperative recurrences of HCC are intrahepatic; pulmonary metastases account for the highest proportion of extrahepatic metastases, and intra-abdominal metastases are relatively rare, with an incidence of $2 \%-16 \%{ }^{2}$ Currently, it is generally believed that intra-abdominal metastasis of $\mathrm{HCC}$ indicates end-stage $\mathrm{HCC}$, and the median survival time is generally less than 1 year. $^{3}$ For these patients, there is currently no unified treatment standard. Staging of HCC with abdominal metastasis, according to the 8th edition of the cancer staging system issued by the International Union for Cancer Control and American 
Joint Committee on Cancer (AJCC), ${ }^{4}$ abdominal metastasis belongs to stage IV, or Barcelona stage $\mathrm{C}^{5}$ targeted therapy such as sorafenib is preferred. According to the Guidelines for the Diagnosis and Treatment of Primary HCC in China (2019 edition), HCC with abdominal metastasis belongs to stage IIIb, ${ }^{6}$ the first choice for treatment is systemic therapy, transcatheter arterial chemoembolization (TACE), or radiotherapy. However, it has also been reported that the median survival time of patients with abdominal metastasis after reresection is as long as 34.5 months. In view of this situation, we retrospectively analyzed the $\mathrm{HCC}$ cases with postoperative abdominal metastasis that were surgically resected in our center over the past 10 years. Our treatment experience is summarized below in the hope that it will be helpful in clinical work.

\section{Objects and Method Case Data}

From January 2010 to January 2020, a total of 2178 cases of HCC were resected in the Department of Hepatobiliary and Pancreatic Surgery, Li Huili Hospital of Ningbo Medical Center, China. Of these, 30 cases with intraabdominal metastases after $\mathrm{HCC}$ resection were surgically resected; 12 of these cases were excluded because resection was performed for biopsy, and 3 cases of abdominal lymph node metastasis were excluded. The remaining 15 cases of HCC with intra-abdominal metastasis after resection that underwent re-resection were included in this study (Figure 1). The inclusion criteria were as follows: (1) patients older than 18 years of age; (2) patients with intra-abdominal metastasis of HCC confirmed by pathology and with complete surgical resection of the metastatic lesions; and (3) patients with no severe heart or lung diseases. The exclusion criteria were as follows: (1) patients with abdominal metastases pathologically confirmed as non-HCC, including cholangiocarcinoma or mixed HCC; (2) patients undergoing resection for abdominal metastasis biopsy or palliative resection; and (3) patients with a previous history of other malignant tumors. This study was approved by the Ethics Committee of Ningbo Medical Centre Lihuili Hospital (KY2021PJ062), and informed consent for the review of medical records from patient was waived because of the retrospective nature of the study. All the patients or the immediate family members of liver donors signed informed consent statement for the liver donations. The study protocol also complied with the ethical standards established by the

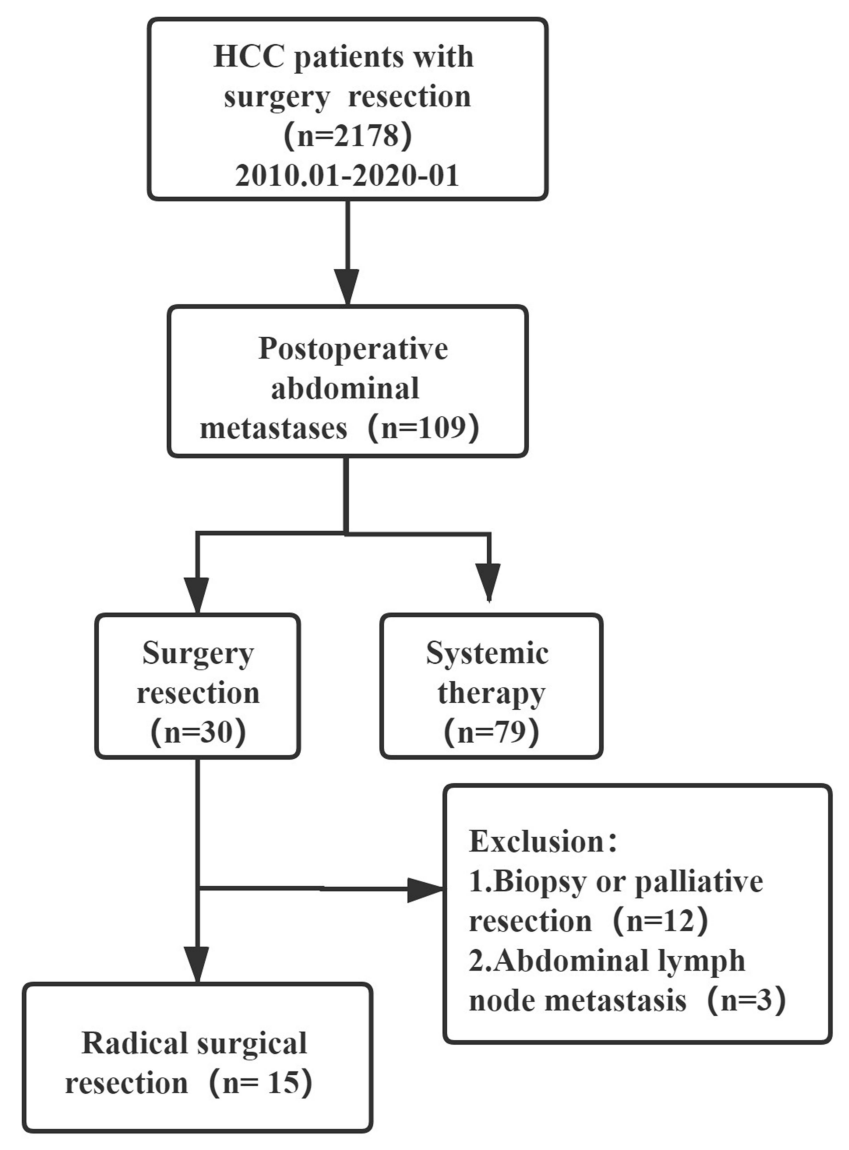

Figure I Patient flow diagram.

Declaration of Helsinki in terms of patient data confidentiality. In this study, donor livers were sourced from people who volunteered to donate their organs after death; the organs were distributed through the Chinese human organ distribution and sharing computer system, no organs came from condemned prisoners, and it was conducted in accordance with the Declaration of Istanbul.

\section{Surgical Methods}

All 15 patients had undergone radical resection of $\mathrm{HCC}$ in the past, including 2 cases of laparoscopic HCC resection, 12 cases of open liver resection, and 1 case of allogeneic liver transplantation. Laparotomy was performed in 14 cases of abdominal metastases, and 1 patient underwent laparoscopic resection of abdominal metastases. All patients who underwent radical resection did not receive systemic therapy.

\section{Postoperative Follow-Up and Treatment}

After discharge, the patients were followed up by telephone or at outpatient or inpatient visits to collect information about their general condition, the recurrence and 


\begin{tabular}{|c|c|c|c|c|c|c|c|c|c|c|c|}
\hline 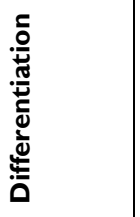 & $\overline{\bar{s}}^{\overline{0}}$ & 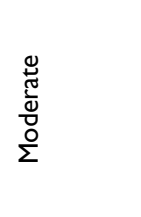 & 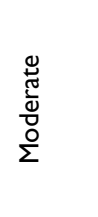 & 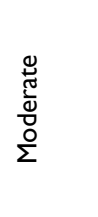 & 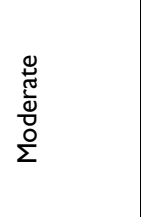 & $\begin{array}{l}\grave{\partial} \\
\text { o }\end{array}$ & 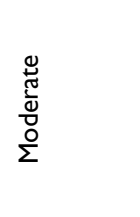 & 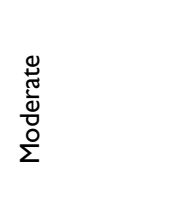 & 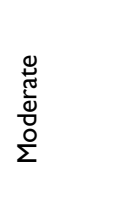 & 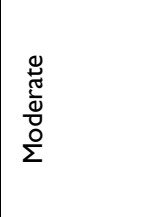 & ¿̀̀ \\
\hline 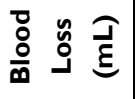 & ষ্ণ & ¿ & 으 & 으 & ষ্ণ & 으 & ষ্ল & : & \&্+ & 으 & ㅇ \\
\hline 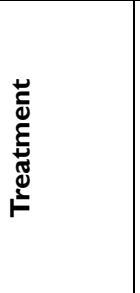 & 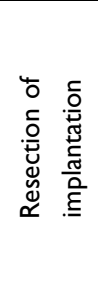 & 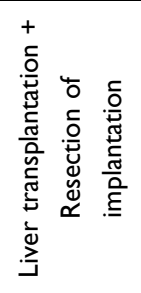 & 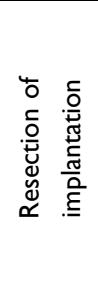 & 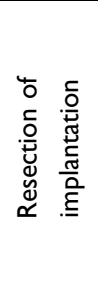 & 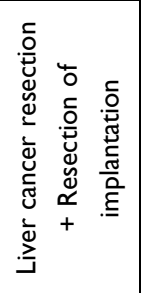 & 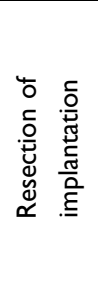 & 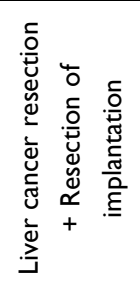 & 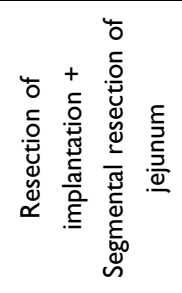 & 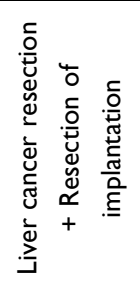 & 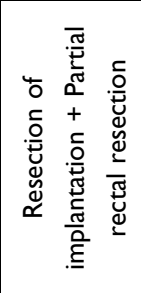 & 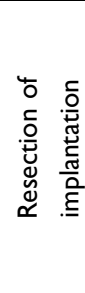 \\
\hline 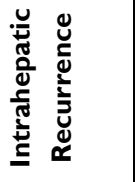 & $\stackrel{\circ}{z}$ & $\stackrel{\mathscr{\Perp}}{\tau}$ & $\stackrel{\circ}{z}$ & $\stackrel{\circ}{z}$ & 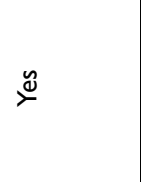 & ㅇ & $\stackrel{\check{\Perp}}{\nu}$ & $\stackrel{\circ}{z}$ & $\stackrel{\mathscr{y}}{\check{\nu}}$ & z & 으 \\
\hline 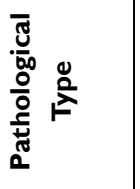 & $\underset{U}{U}$ & $\underset{\cup}{U}$ & $\underset{\mathrm{U}}{\mathrm{U}}$ & $\underset{U}{U}$ & $\underset{\cup}{U}$ & $\underset{\mathrm{U}}{\mathrm{U}}$ & $\stackrel{U}{U}$ & $\underset{U}{U}$ & $\underset{\mathrm{U}}{\mathrm{U}}$ & $\underset{U}{U}$ & $\stackrel{U}{Y}$ \\
\hline 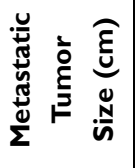 & $\stackrel{\circ}{\text { O }}$ & $\stackrel{\circ}{\dot{m}}$ & - & 0 & $\nabla$ & $\stackrel{\sim}{\sim}$ & $r$ & $\stackrel{\infty}{\sigma}$ & $\stackrel{\circ}{m}$ & $\stackrel{\infty}{-}$ & 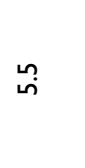 \\
\hline 咅 & - & - & $m$ & - & $N$ & - & - & $\sim$ & - & N & N \\
\hline 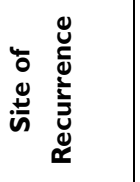 & 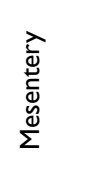 & 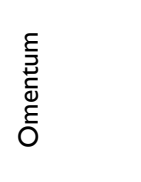 & 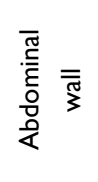 & 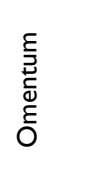 & 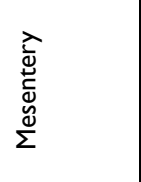 & 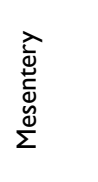 & 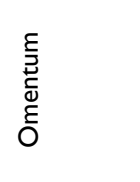 & 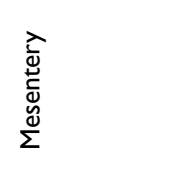 & 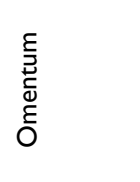 & 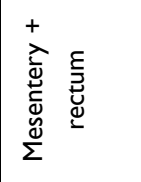 & 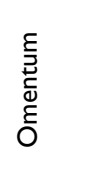 \\
\hline 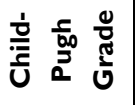 & $\varangle$ & $\varangle$ & $\ll$ & $\varangle$ & $\varangle$ & $\varangle$ & $\varangle$ & $\varangle$ & $\varangle$ & $\varangle$ & $\varangle$ \\
\hline 仓̊ & 0 & - & - & 0 & 0 & 0 & 0 & 0 & 0 & 0 & 0 \\
\hline ڤ̊ & $\frac{0}{\Sigma}$ & $\frac{0}{\Sigma}$ & $\frac{\frac{0}{N}}{\Sigma}$ & $\frac{0}{\sum}$ & $\frac{0}{\Sigma}$ & $\frac{0}{\sum}$ & $\frac{\frac{0}{\pi}}{\Sigma}$ & $\frac{\frac{0}{\pi}}{\Sigma}$ & $\frac{0}{\sum}$ & $\frac{0}{\Sigma}$ & $\frac{\frac{0}{\pi}}{\sum}$ \\
\hline 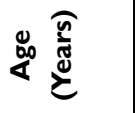 & 8 & $q$ & นn & in & ৪ & $\stackrel{\infty}{\infty}$ & $\hat{\sim}$ & $\hat{f}$ & in & in & กิ \\
\hline 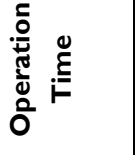 & 商 & 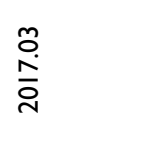 & $\frac{\mathfrak{n}}{\frac{i}{2}}$ & $\begin{array}{l}\stackrel{+}{0} \\
\stackrel{i}{0}\end{array}$ & 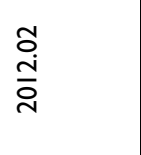 & $\frac{\overline{\bar{i}}}{\overline{\mathrm{N}}}$ & $\begin{array}{l}\stackrel{0}{0} \\
\stackrel{0}{0}\end{array}$ & $\begin{array}{l}\overline{\bar{i}} \\
\bar{i}\end{array}$ & $\begin{array}{l}\stackrel{\infty}{0} \\
\stackrel{0}{0}\end{array}$ & $\begin{array}{l}\stackrel{n}{0} \\
\text { in } \\
\grave{2}\end{array}$ & 商 \\
\hline ֻू & - & $N$ & $m$ & $\sigma$ & in & 0 & 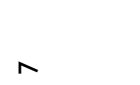 & $\infty$ & $a$ & 으 & $=$ \\
\hline
\end{tabular}




\begin{tabular}{|c|c|c|c|c|}
\hline 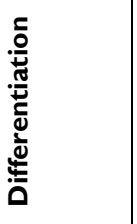 & $\begin{array}{l}\stackrel{亠}{0} \\
\stackrel{\circ}{\circ}\end{array}$ & 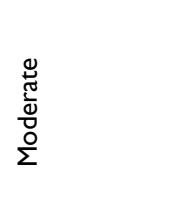 & $\begin{array}{l}\text { ̀े } \\
\text { O }\end{array}$ & 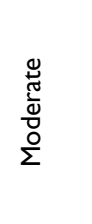 \\
\hline 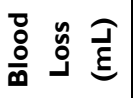 & 으 & ষ্ণ & 으 & 움 \\
\hline 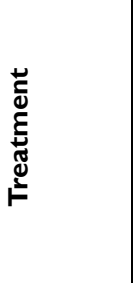 & 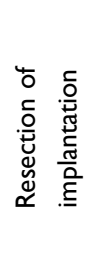 & 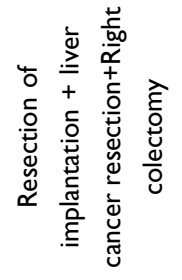 & 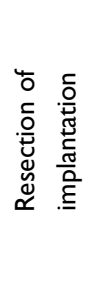 & 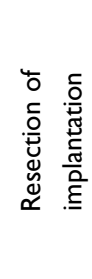 \\
\hline 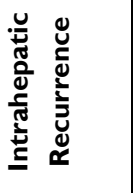 & ㄹ & $\stackrel{\mathscr{\Perp}}{\succ}$ & ㅇ & $\overbrace{\nu}^{\mathscr{y}}$ \\
\hline 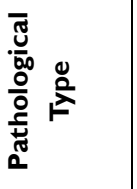 & $\underset{\cup}{U}$ & $\underset{U}{U}$ & $\underset{\cup}{\cup}$ & $\underset{\mathrm{U}}{\cup}$ \\
\hline 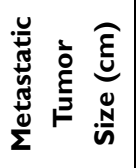 & $\stackrel{m}{m}$ & - & $\bar{i}$ & $\stackrel{\simeq}{\simeq}$ \\
\hline है & $m$ & $N$ & - & $\sigma$ \\
\hline 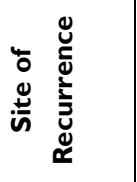 & 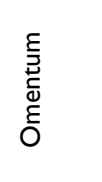 & 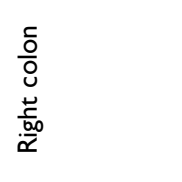 & 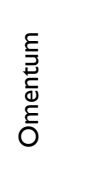 & 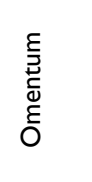 \\
\hline 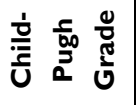 & $\varangle$ & $\ll$ & $\varangle$ & $\varangle$ \\
\hline 仓̊ & - & - & 0 & 0 \\
\hline$\stackrel{\times}{凶}$ & $\frac{\frac{0}{\pi}}{\Sigma}$ & $\frac{\frac{0}{\pi}}{\sum}$ & $\frac{0}{\sum \pi}$ & $\frac{\frac{0}{N}}{\Sigma}$ \\
\hline 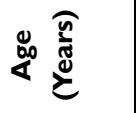 & $\overline{6}$ & $\hat{f}$ & คำ & $\mathscr{f}$ \\
\hline 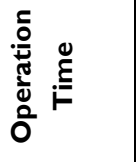 & 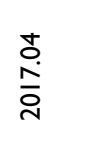 & $\frac{\bar{N}}{\bar{n}}$ & 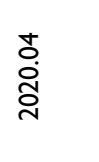 & 뭄 \\
\hline Uू & $\simeq$ & $\underline{m}$ & \pm & $\underline{\underline{n}}$ \\
\hline
\end{tabular}

metastasis of HCC, and survival. The methods used to monitor the recurrence and metastasis of HCC included serum $\alpha$-fetoprotein (AFP) detection (once a month for 6 months after surgery, once every 2 months from 6 months to 1 year after surgery, and once every 3 months after 1 year) and abdominal hepatobiliary B-ultrasound (once a month for 6 months after surgery and once every 3 months after 6 months), chest computed tomography (CT) and abdominal enhanced magnetic resonance imaging (MRI) examinations (once every 3 months for 1 year after surgery and once every 6 months after 1 year). Patients diagnosed with postoperative intrahepatic recurrence or extrahepatic metastasis of HCC were treated with surgical resection, intervention, and targeted treatment according to the specific conditions. The start of the follow-up was the day of the abdominal metastasis resection, and the end was January 31, 2021. The disease-free survival (DFS) time was the time between the start of surgery and tumor recurrence or the last follow-up. The OS time was defined as the time from surgery to death or to the last follow-up. The follow-up time ranged from 8 to 130 months, with an average of 33.2 months.

\section{Statistical Analysis}

Data analysis in this study was performed using SPSS software, version 22.0 (IBM Inc., Armonk, NY, USA). The survival analysis was performed using the KaplanMeier method. $P<0.05$ was considered statistically significant.

\section{Result}

\section{Patient Demographic Characteristics and} General Information

The 15 patients were all males, with a median age of 55 (47, 60) years old. The Eastern Cooperative Oncology Group (ECOG) score was 0 in 11 cases and 1 in 4 cases. The ChildPugh scores were all grade A. All patients underwent repeat surgery due to recurrence after the first resection of HCC; for 11 cases, the surgery was the first abdominal resection of metastases; for 3 cases, it was the second resection of metastases; and for 1 case, it was the third resection. Regarding the surgical methods, 14 cases underwent laparotomy, and 1 case underwent laparoscopic surgery. There were 8 cases of simple metastasis resection and 5 cases of combined liver metastasis resection; of the combined resections, 1 patient underwent liver transplantation; 1 patient underwent $\mathrm{HCC}$ resection, abdominal metastasis resection, 
Table 2 Laboratory Data of the 15 Patients with Resected Peritoneal Dissemination

\begin{tabular}{|c|c|c|c|c|c|c|c|c|}
\hline Case & Hb $(g / L)$ & HBsAg & PT (Sec) & Albumin (g/L) & Bil $(T)(\mu \mathrm{mol} / \mathrm{L})$ & ALT (U/L) & AST (U/L) & AFP $(\mu g / L)$ \\
\hline I & 156 & + & 11.4 & 40.0 & 15.6 & 11 & 15 & 1.6 \\
\hline 2 & 164 & + & 12.9 & 51.5 & 34 & 31 & 33 & 5.2 \\
\hline 3 & $|5|$ & + & 11.2 & 46.0 & 14.7 & 32 & 37 & 268.9 \\
\hline 4 & 162 & + & 11.4 & 39.5 & 11.2 & 18 & 13 & 2.7 \\
\hline 5 & 143 & - & 12.3 & 39.3 & 10.3 & 24 & 23 & 3.4 \\
\hline 6 & 119 & + & 12.7 & 38.9 & 11.0 & 12 & 16 & 136.5 \\
\hline 7 & 143 & + & 10.7 & 42.0 & 8.3 & 15 & 13 & 423.6 \\
\hline 8 & 136 & + & 11.6 & 38.9 & 11.2 & 42 & 40 & 564.3 \\
\hline 9 & 126 & + & 12.3 & 39.9 & 7.9 & 23 & 21 & 615.2 \\
\hline 10 & 137 & + & 11.4 & 40.2 & 6.3 & 12 & 16 & 113.6 \\
\hline 11 & 129 & + & 11.6 & 41.9 & 5.6 & 22 & 26 & 672.7 \\
\hline 12 & 134 & - & 12.6 & 38.7 & 24.8 & 21 & 53 & 37.9 \\
\hline 13 & $|5|$ & - & II.I & 38.8 & 6.0 & 16 & 17 & 292.1 \\
\hline 14 & 147 & + & 11.6 & 40.0 & 9.0 & 14 & 20 & 2411.2 \\
\hline 15 & 132 & - & 12.6 & 43.5 & 8.6 & 31 & 45 & 85.9 \\
\hline
\end{tabular}

Abbreviations: Hb, hemoglobin; PT, prothrombin time; Bil, bilirubin; T, total; ALT, alanine aminotransferase; AST, aspartate aminotransferase; AFP, alfa fetoprotein.

and right colectomy; 1 patient underwent abdominal metastasis resection and Segmental resection of jejunum; and 1 patient underwent abdominal metastasis resection and partial rectal resection (Table 1).

\section{Preoperative Laboratory Examination}

All 15 patients underwent routine laboratory tests before surgery, including routine blood, biochemical, hepatitis $\mathrm{B}$ virus markers, serum AFP, and coagulation function tests. Among them, 11 patients had hepatitis B infection. None of the patients showed significant abnormalities in the blood routine and biochemistry; 11 patients had higher than normal preoperative serum AFP, and the highest AFP level was $2411.2 \mathrm{ug} / \mathrm{L}$ (Table 2).

\section{Pathological Characteristics of the First Surgery}

Among the 15 patients, 13 underwent laparotomy, and 2 underwent laparoscopic surgery. The resected tumors had a median diameter of $4.5(2.5,5.7) \mathrm{cm}$. The degree of tumor differentiation was as follows: 1 case with high differentiation, 10 cases with moderate differentiation, and 4 cases with poor differentiation. Twelve patients had solitary tumors, and 3 patients had multiple tumors. Regarding the microvascular invasion (MVI) classification, there were 2 cases of grade 0,8 cases of grade 1 , and 5 cases of grade 2. At the time of the first surgery, 3 patients had liver tumors that had broken through the liver capsule, 12 patients had tumor resection margins that exceeded $1 \mathrm{~cm}$, and 3 patients had resection margins within $1 \mathrm{~cm}$. There were 6 cases of grade 2 liver fibrosis, 6 cases of grade 3 liver fibrosis, and 3 cases of grade 4 liver fibrosis. Two patients had a history of hepatic rupture (Table 3).

\section{Distribution Characteristics of Abdominal Metastatic Tumors}

Eight patients were diagnosed with abdominal metastasis after HCC resection based on enhanced CT (Figure 2). Five patients had no abdominal metastasis on MRI (Figure 3) examination; 2 patients had no abdominal metastasis on preoperative MRI and positron emission tomography (PET)CT examination, but intra-abdominal metastasis of HCC was found during surgery. Greater omental metastasis accounted for the majority of the metastasis sites, with a total of 8 cases. There were 4 cases of mesenteric metastases, 1 case of abdominal wall metastasis, 1 case of mesentery plus rectum metastasis, and 1 case of right colon metastasis. The largest number of metastases was 4 . There were 7 cases of solitary metastasis, 5 cases of 2 metastases, 2 cases of 3 metastases, and 1 case of 4 metastases (Figures 1-3).

\section{Survival Prognosis Analysis}

For 2178 patients who were treated by resection, the 1-, 3-, and 5-year DFS rates were $79.4 \%, 54.4 \%$, and $53.8 \%$, respectively, and metastases-free survival rates were $82.9 \%, 62.9 \%$, and $45.3 \%$, respectively. During the follow-up period, the postoperative 1-, 3-, and 5-year DFS 
Table 3 Pathological Characteristics of the First Surgery

\begin{tabular}{|c|c|c|c|c|c|c|c|c|c|}
\hline Case & Size $(\mathrm{cm})$ & Treatment & Differentiation & $\begin{array}{l}\text { Satellite } \\
\text { Lesions }\end{array}$ & MVI & $\begin{array}{c}\text { Liver } \\
\text { Capsule }\end{array}$ & $\begin{array}{c}\text { Section } \\
\text { Margin (cm) }\end{array}$ & $\begin{array}{l}\text { Stage of } \\
\text { Hepatic } \\
\text { Fibrosis }\end{array}$ & Rupture \\
\hline I & 6.5 & Right lobectomy & Well & + & MI & Complete & $>1$ & S3 & No \\
\hline 2 & 4.8 & $\begin{array}{c}\text { Left lateral } \\
\text { segmentectomy }\end{array}$ & Moderate & - & MI & Complete & $<1$ & S4 & No \\
\hline 3 & 6.5 & $\begin{array}{c}\text { Liver } \\
\text { transplantation }\end{array}$ & Moderate & + & Mo & Complete & $>1$ & S4 & No \\
\hline 4 & 4.5 & Left lobectomy & Moderate & - & MI & Complete & $>1$ & S2 & No \\
\hline 5 & 2.5 & $\begin{array}{l}\text { Local } \\
\text { hepatectomy }\end{array}$ & Moderate & - & MI & Complete & $<1$ & S2 & No \\
\hline 6 & 1.8 & $\begin{array}{c}\text { Local } \\
\text { hepatectomy }\end{array}$ & Poor & - & M2 & Broken & $>1$ & S3 & No \\
\hline 7 & 3.2 & $\begin{array}{c}\text { Left lateral } \\
\text { segmentectomy }\end{array}$ & Moderate & - & MI & Complete & $>1$ & S2 & No \\
\hline 8 & 4.5 & $\begin{array}{l}\text { Right posterior } \\
\text { lobectomy }\end{array}$ & Moderate & - & $M 2$ & Broken & $>1$ & S2 & Yes \\
\hline 9 & 3.0 & Left lobectomy & Moderate & - & MI & Complete & $>1$ & S2 & No \\
\hline 10 & 2.5 & $\begin{array}{c}\text { Left lateral } \\
\text { segmentectomy }\end{array}$ & Moderate & - & $M 2$ & Complete & $>1$ & S3 & No \\
\hline II & 8.5 & $\begin{array}{c}\text { Liver } \\
\text { transplantation }\end{array}$ & Moderate & - & M2 & Complete & $>1$ & S4 & No \\
\hline 12 & 5.5 & $\begin{array}{c}\text { Liver } \\
\text { transplantation }\end{array}$ & Poor & + & $M 2$ & Broken & $>1$ & S3 & No \\
\hline 13 & 5.7 & $\begin{array}{l}\text { Local } \\
\text { hepatectomy }\end{array}$ & Moderate & - & MI & Complete & $>1$ & S3 & Yes \\
\hline 14 & 2.5 & $\begin{array}{l}\text { Left caudate } \\
\text { lobectomy }\end{array}$ & Poor & - & Mo & Complete & $<1$ & S2 & No \\
\hline 15 & 4.5 & $\begin{array}{c}\text { Local } \\
\text { hepatectomy }\end{array}$ & Poor & - & MI & Complete & $>1$ & S3 & No \\
\hline
\end{tabular}

Abbreviation: MVI, microvascular invasion.

rates of the 15 patients were $31.1 \%, 23.3 \%$, and $11.7 \%$, respectively, and the 1-, 3-, and 5-year OS rates were $93.3 \%, 28.7 \%$, and $19.1 \%$, respectively (Figure 4). At the end of follow-up, 12 patients died, all of HCC recurrence, and 3 patients survived (130.4 months, 43.3 months, and 9.4 months, respectively, Table 4). Currently, there are no cases of intrahepatic recurrence or extrahepatic metastasis.

\section{Discussion}

HCC combined with extrahepatic metastasis is commonly encountered in clinical practice. Autopsy examinations of
HCC patients show that the incidence of $\mathrm{HCC}$ metastasis is as high as $64 \% .^{7}$ Distant metastasis of HCC is mainly blood metastasis but can include lung, bone, adrenal gland, and brain metastasis. Lymphatic system metastasis is relatively rare. Most peritoneal metastases are caused by peritoneal implantation of the tumor after HCC rupture and bleeding or the dissemination of tumor tissues in the peritoneal cavity during the first resection of HCC; in contrast, cases of unruptured tumors combined with peritoneal metastases found for the first time are less common. All 15 patients in this study were found to have intra- 


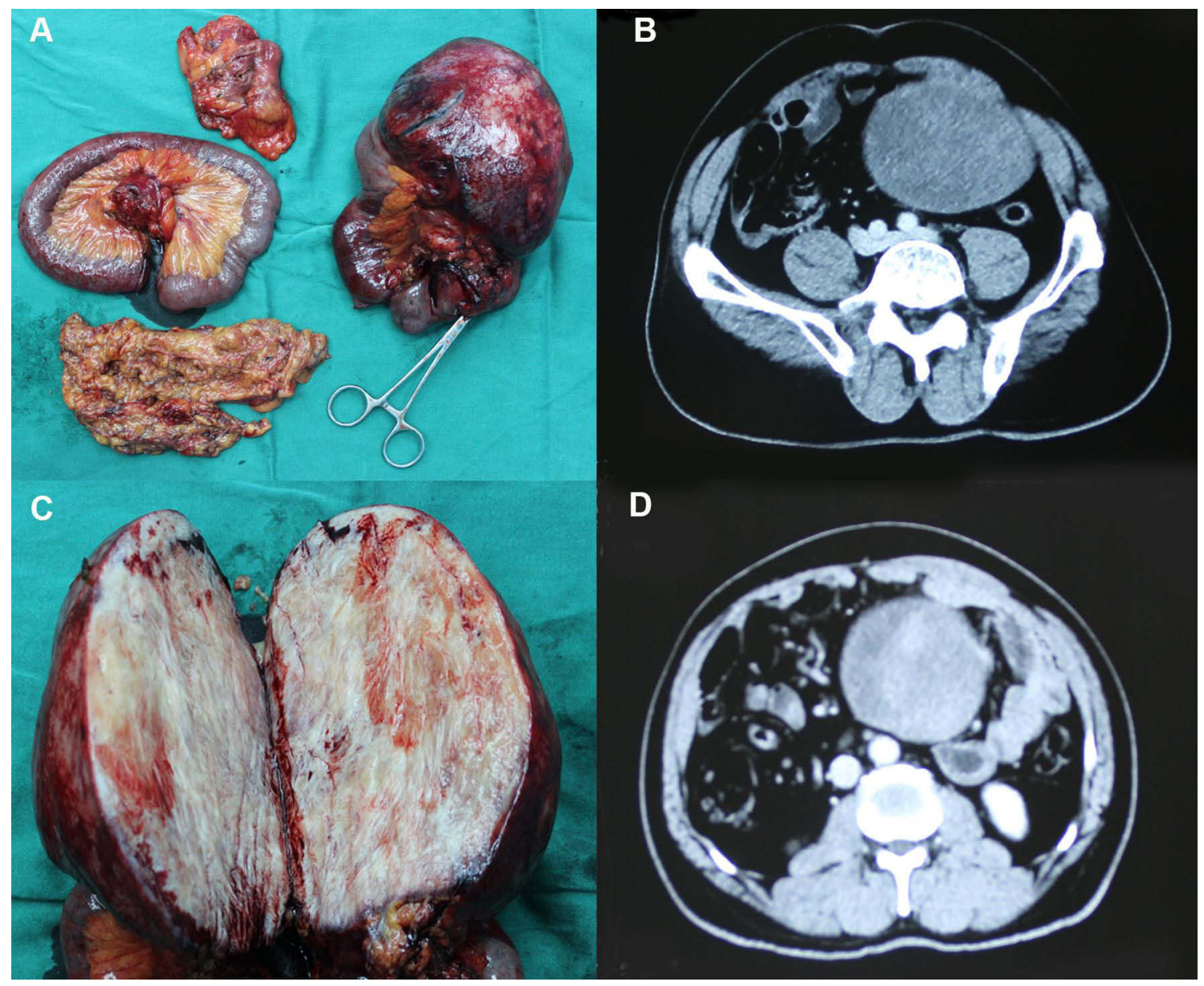

Figure 2 Clinical picture of patient I. (A) Giant metastatic tumor of mesentery; (B) Computed tomography (CT) images; (C) Tumor section specimen; (D) Arterial dominant phase of CT shows arterial enhancement of nodule measuring $10.0 \mathrm{~cm}$ in diameter.

abdominal metastases during follow-up after the first resection of HCC. The main route of intraabdominal metastasis of HCC is still direct tumor invasion or planting metastasis. Sometimes 2 types of metastasis are present at the same time, and the most common site of metastasis is the omentum. ${ }^{8,9}$ There are also different forms of metastasis, including solitary intra-abdominal metastasis, multiple focal intra-abdominal metastasis, and intra-abdominal diffuse metastasis. In the first two cases, surgical resection can generally be performed, while for intra-abdominal diffuse metastasis, it is difficult to achieve complete resection of the tumors visible to the naked eye. Among the 15 patients in this study, 7 had a solitary intra-abdominal metastasis, and 8 had multiple focal metastases. One patient had 4 intra-abdominal metastases. However, complete resection of the metastases was achieved in all cases, including 8 cases of omental resection and 2 cases of combined partial colon or rectal resection. Among the 15 patients with abdominal metastases, 2 had a history of liver tumor rupture and hemorrhage, which may a reason for intra-abdominal metastasis of HCC. Tumor rupture and hemorrhage was also observed in metastatic tumors, including 1 case of abdominal metastatic tumor rupture and hemorrhage resulting in hemorrhagic peritonitis, for which emergency surgical treatment was performed.

In terms of staging of $\mathrm{HCC}$ with abdominal metastasis, according to the 8th edition of the cancer staging system ${ }^{4}$ issued by the International Union for Cancer Control and American Joint Committee on Cancer (AJCC), abdominal metastasis belongs to stage IV, or Barcelona stage C. ${ }^{5}$ According to the Guidelines for the Diagnosis and Treatment of Primary HCC in China (2019 edition), ${ }^{6}$ HCC with abdominal metastasis belongs to stage IIIb. For stage IV HCC, the first choice for treatment is systemic therapy, transcatheter arterial chemoembolization (TACE), or radiotherapy. However, in clinical practice, some surgeons still choose to surgically remove primary and metastatic lesions before starting systemic treatment. ${ }^{10}$ 


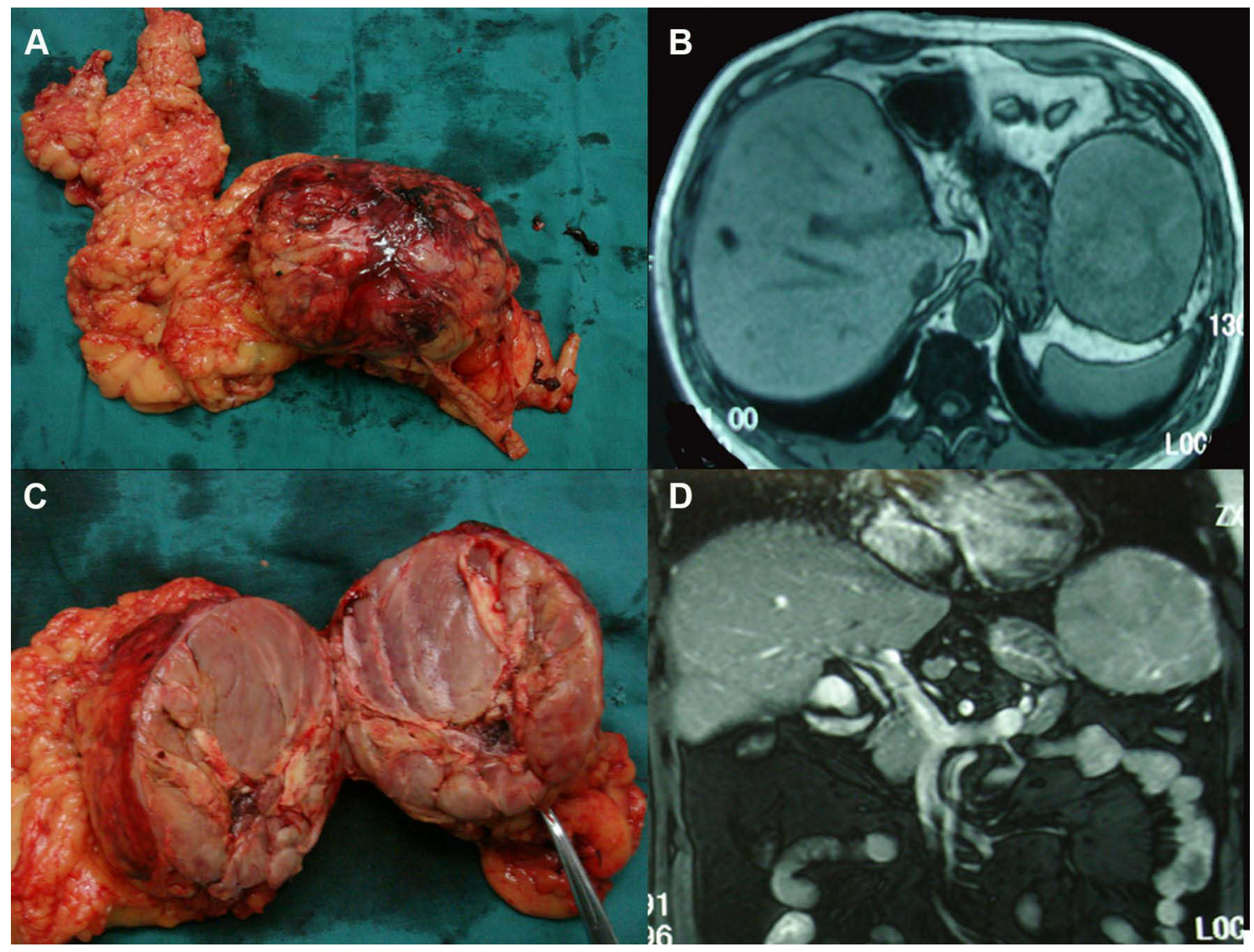

Figure 3 Clinical picture of patient 4. (A) Giant metastatic tumor of omentum; (B) Horizontal plane of magnetic resonance images; (C) Tumor section specimen; (D) Coronal plane of magnetic resonance imaging.

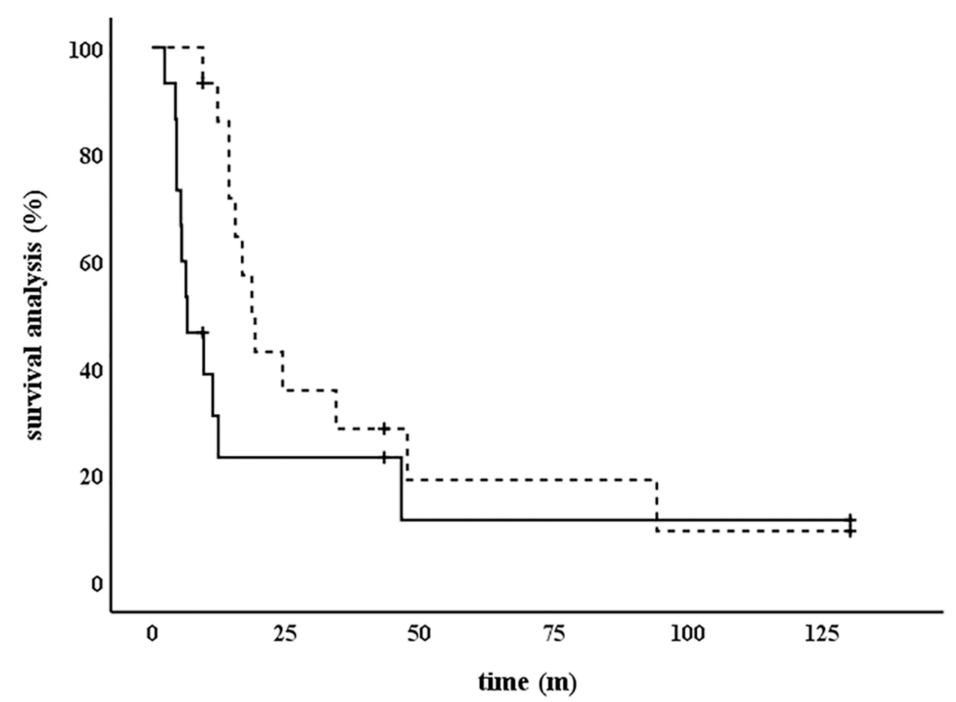

Figure 4 The survival rate after resection of the abdominal metastases.

Abbreviations: DFS, disease-free survival; OS, overall survival. 
Table 4 Postoperative Survival of the Patients

\begin{tabular}{|l|c|c|c|c|}
\hline Case & $\begin{array}{c}\text { Treatment of Re- } \\
\text { Recurrence }\end{array}$ & $\begin{array}{c}\text { DFS } \\
(\mathbf{m})\end{array}$ & $\begin{array}{c}\text { OS } \\
\mathbf{( m )}\end{array}$ & Status \\
\hline I & - & 43.3 & 43.3 & $\begin{array}{c}\text { Free of } \\
\text { disease }\end{array}$ \\
3 & Sorafenib+Lenvatinib & 9.6 & 34.3 & Dead \\
4 & Sorafenib+Regorafenib & 5.5 & 47.6 & Dead \\
5 & Sorafenib & 46.5 & 94.2 & Dead \\
6 & Sorafenib & 11.3 & 15.5 & Dead \\
7 & Sorafenib & 12.3 & 16.8 & Dead \\
8 & - & 130.3 & 130.3 & Free of \\
& & 4.5 & 9.4 & Dead \\
9 & Sorafenib & 6.5 & 14.3 & Dead \\
10 & None & 4.5 & 18.6 & Dead \\
II & Sorafenib & 5.3 & 14.3 & Dead \\
I2 & Sorafenib & 4.3 & 24.3 & Dead \\
13 & Sorafenib+Regorafenib & 2.3 & 12.2 & Dead \\
14 & Sorafenib & 9.4 & 9.4 & Free of \\
& - & & & disease \\
15 & Sorafenib+Apatinib & 6.3 & 19.2 & Dead \\
\hline
\end{tabular}

Abbreviations: DFS, disease-free survival; OS, overall survival.

Currently, there is no unified standard for the treatment of postoperative abdominal metastasis of HCC. Various guidelines and standards do not specifically describe whether surgical treatment should be performed for resectable intra-abdominal metastases.

At present, most studies on the re-resection of abdominal metastasis after HCC surgery are case reports. There are few serial studies; there were only 5 studies published from 2002 to 2014. The median survival time was from 13.8 months to 34.5 months, and the highest 5-year survival rate was $48 \%$ (Table 5). Studies have reported the long-term survival of HCC patients after abdominal metastasis resection. ${ }^{11-13}$ Yeh et $\mathrm{al}^{9}$ studied 16 abdominal metastasis patients and found that the OS time of the patients with solitary abdominal metastasis without intrahepatic recurrence was similar to that of patients without recurrence. Some studies have further shown that HCC patients with postoperative abdominal metastasis but without intrahepatic recurrence or with intrahepatic lesions that can be effectively controlled have a good postoperative prognosis and should be actively treated with surgery; furthermore, the number of abdominal metastases may not be the main prognostic factor. ${ }^{15,16} \mathrm{Kow}$ et al ${ }^{17}$ conducted a study of 36 patients with abdominal metastases and found that the median survival time of patients who underwent abdominal metastasis resection after HCC surgery was significantly improved compared with that of patients who did not undergo surgical resection ( 33 vs $14 \mathrm{~m}$ ), and the prognosis was better for patients with abdominal metastases found more than 6 months after the first surgery and with a solitary or limited abdominal metastasis. A study conducted by the Japanese Society of Hepato-BiliaryPancreatic Surgery of 99 patients from 44 institutions in Japan showed that the number and size of abdominal metastases affected the prognosis. The 5-year OS rate of patients with an abdominal cancer index (PCI) $\leq 6$ and no residual tumor was $43 \%$, and their prognosis was much better than that of patients who did not meet those criteria. ${ }^{18}$

In this study, the median survival time of the 15 patients was 18.6 months, and the median DFS time was 6.5 months. Among these patients, 3 had a DFS of more than 5 years. All 3 patients had intra-abdominal solitary metastasis and no history of intrahepatic tumor rupture. For intra-abdominal metastases, the prognosis is better when the lesion is solitary or localized. In the 2 patients with intestinal wall metastasis, postoperative specimen examinations showed intestinal stenosis. If the abdominal metastases had not been resected, intestinal obstruction symptoms would likely have developed. For these patients, resection of abdominal metastases may be acceptable and may improve their quality of life. The median survival time of our patients with abdominal metastasis after HCC surgery is better than that reported in the literature, especially some patients with isolated or limited metastasis achieve long-term disease-free survival, and obtain a relatively good prognosis.

Table 5 Median Survival of Abdominal Metastases of Hepatocellular Carcinoma in the Literature

\begin{tabular}{|l|l|l|l|l|l|l|}
\hline No & Author & $\mathbf{n}$ & Area & Year & 5-Year Os & Median Survival (Months) \\
\hline 1 & Yeh et al $^{9}$ & 16 & Taiwan & 2002 & - & 16.0 \\
2 & Lin et al $^{14}$ & 8 & Taiwan & 2009 & - & 13.8 \\
3 & Hashimoto et al $^{15}$ & 9 & Japan & 2012 & $42.0 \%$ & - \\
4 & Takemura et al $^{16}$ & 32 & Japan & 2014 & $39.0 \%$ & 34.5 \\
5 & Kow et al $^{17}$ & 13 & Singapore & 2012 & $48.0 \%$ & 33.0 \\
\hline
\end{tabular}


This study was retrospective and had the selection bias inherent to such studies. Because the surgery was exploratory, the total number of surgical resections of abdominal metastases after HCC surgery was small, and therefore, the sample size of the study was small. In the future, some large-scale multicenter prospective studies may be needed to clarify the significance of the resection of abdominal metastases after HCC surgery.

With the application of immunosuppressive agents in HCC and the widespread development of multidisciplinary diagnosis and treatment models, there are an increasing number of systemic treatment methods for advanced HCC. Choosing the best treatment regimen for the individual patient is the biggest problem facing clinicians today. Surgery should still be chosen with caution given that the current major guidelines do not recommend surgery for metastatic tumors.

However, for relatively limited intra-abdominal or solitary metastatic lesions, some patients can attain a good prognosis with the simultaneous resection of metastases. For patients with intestinal wall metastasis, we recommend partial intestinal resection followed by systematic treatment, which can hopefully improve the quality of life of these patients.

\section{Data Sharing Statement}

The datasets used and/or analysed in this study are available from the corresponding author on reasonable request.

\section{Ethics Statement}

This study was approved by the Ethics Committee of Ningbo Medical Centre Lihuili Hospital (KY2021PJ062), and informed consent for the review of medical records from patient was waived because of the retrospective nature of the study. All the patients or the immediate family members of liver donors signed informed consent statement for the liver donations. The study protocol also complied with the ethical standards established by the Declaration of Helsinki in terms of patient data confidentiality.

\section{Funding}

There is no funding to report.

\section{Disclosure}

Jiong-Ze Fang and Yong Yang are co-first authors for this study. The authors report no conflicts of interest in this work.

\section{References}

1. Wild CP, Weiderpass E, Stewart BW. World Cancer Report: Cancer Research for Cancer Prevention. Lyon: International Agency for Research on Cancer; 2020.

2. Kow AW, Kwon CH, Song S, et al. Clinicopathological factors and long-term outcome comparing between lung and peritoneal metastasectomy after hepatectomy for hepatocellular carcinoma in a tertiary institution. Surgery. 2015;157(4):645-653. doi:10.1016/j. surg.2014.07.024

3. Uchino K, Tateishi R, Shiina S, et al. Hepatocellular carcinoma with extrahepatic metastasis: clinical features and prognostic factors. Cancer. 2011;117(19):4475-4483. doi:10.1002/cncr.25960

4. Chun YS, Pawlik TM, Vauthey JN, et al. 8th Edition of the AJCC cancer staging manual: pancreas and hepatobiliary cancers. Ann Surg Oncol. 2018;25(4):845-847. doi:10.1245/s10434-017-6025-x

5. Llovet JM, Bru C, Bruix J. Prognosis of hepatocellular carcinoma: the BCLC staging classification. Semin Liver Dis. 1999;19 (3):329-338. doi:10.1055/s-2007-1007122

6. Bureau of Medical Administration, National Health Commission of the People's Republic of China. Guidelines for diagnosis and treatment of primary liver cancer(Version 2019). Chin J Pract Surg. 2020;40(2):121-138.

7. Nakashima T, Okuda K, Kojiro M, et al. Pathology of hepatocellular carcinoma in Japan. 232 consecutive cases autopsied in ten years. Cancer. 1983;51(5):863-877. doi:10.1002/1097-0142(19830301) 51:5<863::AID-CNCR2820510520>3.0.CO;2-D

8. Kwak MS, Lee JH, Yoon JH, et al. Risk factors, clinical features, and prognosis of the hepatocellular carcinoma with peritoneal metastasis. Dig Dis Sci. 2012;57(3):813-819. doi:10.1007/s10620-011-1995-1

9. Yeh C, Chen M, Jen L. Resection of peritoneal implantation from hepatocellular carcinoma. Ann Surg Oncol. 2002;9(9):863-868. doi:10.1007/BF02557522

10. Berger Y, Spivack JH, Heskel M, et al. Extrahepatic metastasectomy for hepatocellular carcinoma: predictors of long-term survival. J Surg Oncol. 2016;114(4):469-474. doi:10.1002/jso.24340

11. Eriguchi N, Aoyagi S, Okuda K, et al. Successful surgical treatment for implanted intraperitoneal metastases of hepatocellular carcinoma. J Hepatobiliary Pancreat Surg. 2007;7(5):520-523. doi:10.1007/ s005340070025

12. Uenishi T, Kubo S, Hirohashi K, et al. Successful surgical control for hepatocellular carcinoma disseminated to the peritoneum: a case report. Hepato-Gastroenterology. 2002;49(44):532.

13. Chou H, Lee K, Yeh C, et al. Long-term survival following resection of peritoneal implantation from hepatocellular carcinoma: a case report. Hepato-Gastroenterology. 2005;52(64):1221.

14. Lin CC, Liang HP, Lee HS., et al. Clinical manifestations and survival of hepatocellular carcinoma patients with peritoneal metastasis. 2009;24(5):815-820. doi:10.1111/j.1440-1746.2009.05848.x

15. Hashimoto MM, Sasaki KM, Moriyama JM, et al. Resection of peritoneal metastases in patients with hepatocellular carcinoma. Surgery. 2013;153(5):727-731. doi:10.1016/j.surg.2012.03.031

16. Takemura N, Hasegawa K, Aoki T, et al. Surgical resection of peritoneal or thoracoabdominal wall implants from hepatocellular carcinoma. Br J Surg. 2014;101(8):1017-1022. doi:10.1002/bjs.9489

17. Kow AWC, Kwon CHD, Song S, et al. Risk factors of peritoneal recurrence and outcome of resected peritoneal recurrence after liver resection in hepatocellular carcinoma: review of 1222 cases of hepatectomy in a tertiary institution. Ann Surg Oncol. 2012;19 (7):2246-2255. doi:10.1245/s10434-012-2260-3

18. Iida H, Tani M, Aihara T, et al. New metastasectomy criteria for peritoneal metastasis of hepatocellular carcinoma: a study of the Japanese Society of Hepato-Biliary-Pancreatic Surgery. J Hepatobiliary Pancreat Sci. 2020;27(10):673-681. doi:10.1002/ jhbp.796 


\section{Publish your work in this journal}

Cancer Management and Research is an international, peer-reviewed open access journal focusing on cancer research and the optimal use of preventative and integrated treatment interventions to achieve improved outcomes, enhanced survival and quality of life for the cancer patient.
The manuscript management system is completely online and includes a very quick and fair peer-review system, which is all easy to use. Visit http://www.dovepress.com/testimonials.php to read real quotes from published authors. 